\title{
Effects of the Optional Protocols to the Convention on the Rights of the Child on the causes of child death: a statistical study on a global scale
}

\author{
Efeitos dos Protocolos Opcionais da Convenção sobre os Direitos da Criança nas causas de \\ morte infantil: um estudo estatístico em escala global
}

Efectos de los Protocolos Facultativos de la Convención sobre los Derechos del Niño sobre las causas de la muerte infantil: un estudio estadístico a escala mundial

\author{
Cíntia da Silva Telles Nichele ${ }^{1}$ \\ Marco Aurelio Pereira Horta ${ }^{2}$
}

Aldo Pacheco Ferreira ${ }^{3}$

\begin{abstract}
The Convention on the Rights of the Child (CRC) and the Optional Protocol to the Convention on the Rights of the Child on a Communications Procedure (OPCP) make commitments and guarantees in relation to child health. The aim of the study is to verify the effects of these commitments on the causes of child death. To analyze these effects, we apply the one-way analysis of variance. For each group, we calculated the averages of child deaths in their respective countries for the years 2002, 2007, 2012, and 2017. The p-value resulting indicated whether there was a difference between the means of child deaths in those years that were compared. We also observed the time series for each cause of death over the years 2000 to 2017. The CRC has an expressive adhesion. OPCP has a smaller number of acceptors in all regions compared to CRC. The acceptance of OPCP did not significantly alter the results of the number of deaths in the accepting countries in any of the 13 causes of child death observed. In the non- accepting group, significant differences were found concerning five causes of child death: HIVIAIDS, diarrhoeal diseases, measles, meningitis/encephalitis, and acute lower respiratory infections ( $p$-values $0.01,0.01,0.003,0.002$, and 0.003 , respectively). Our results suggest that the group of countries that have accepted the OPCP are more committed to issues of child deaths causes studied. In all of them the annual death numbers were considerably lower in this group.
\end{abstract}

\section{Keywords}

Child Health. International Cooperation. Human Rights. Analysis of Variance.

\section{Resumo}

A Convenção sobre os Direitos da Criança e o Protocolo Facultativo à Convenção sobre os Direitos da Criança Relativo a um Procedimento de Comunicações (PFPC) estabelecem

\footnotetext{
${ }^{1}$ Master in Public Health, Sérgio Arouca National School of Public Health, Oswaldo Cruz Foundation, Rio de Janeiro, RJ, Brazil; D.Sc. Student, Department of Human Rights, Health and Cultural Diversity, Sérgio Arouca National School of Public Health, Oswaldo Cruz Foundation, Rio de Janeiro, RJ, Brazil. https://orcid.org/0000-0001-6685-1017. E-mail: cintiatelles.ensp@gmail.com

${ }^{2} \mathrm{PhD}$ in Public Health and Environment, Sérgio Arouca National School of Public Health, Oswaldo Cruz Foundation, Rio de Janeiro, RJ, Brazil; researcher, Oswaldo Cruz Institute, Oswaldo Cruz Foundation, Rio de Janeiro, RJ, Brazil. https://orcid.org/0000-0003-4117-5379. E-mail: marco.horta@fiocruz.br

${ }^{3} \mathrm{PhD}$ in Biomedical Engineering; Coordinator of Graduate Programs in Engineering, Federal University of Rio de Janeiro, Rio de Janeiro, RJ, Brazil; researcher and professor, Department of Human Rights, Health and Cultural Diversity, Sérgio Arouca National School of Public Health, Oswaldo Cruz Foundation, Rio de Janeiro, RJ, Brazil. https://orcid.org/0000-00027122-5042. E-mail: aldoferreira@ensp.fiocruz.br
} 


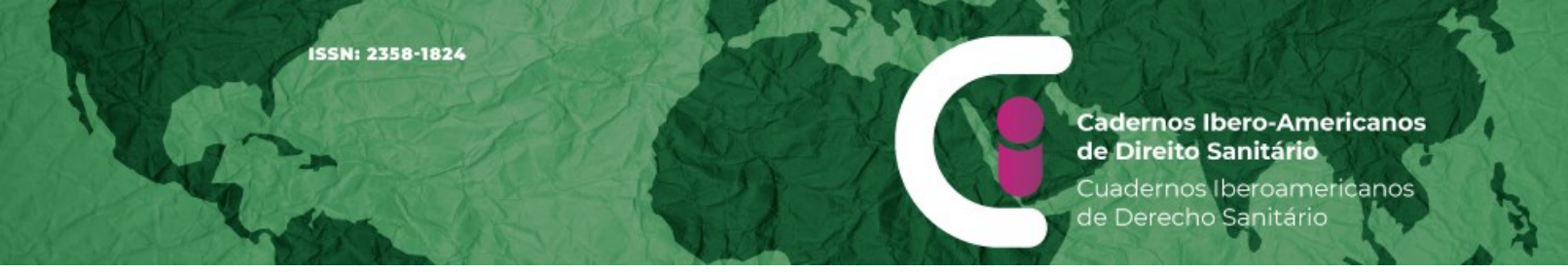

compromissos e garantias em relação à saúde infantil. O objetivo do estudo é verificar os efeitos desses compromissos nas causas de morte infantil. Para analisar esses efeitos, aplicamos a análise de variância unilateral. Para cada grupo, calculamos as médias de óbitos infantis em seus respectivos países para os anos de 2002, 2007, 2012 e 2017. O p-valor resultante indicou se havia diferença entre as médias de óbitos infantis nos anos comparados. Observamos também as séries temporais para cada causa de morte ao longo dos anos de 2000 a 2017. O CRC tem adesão expressiva. O OPCP possui menos adeptos em todas as regiões em comparação ao CRC. A aceitação da OPCP não alterou significativamente os resultados do número de óbitos nos países adeptos em nenhuma das 13 causas de morte infantil observadas. No grupo de não aceitação, foram encontradas diferenças significativas em relação a cinco causas de morte infantil: HIVIAIDS, doenças diarreicas, sarampo, meningite/encefalite e infecções respiratórias agudas inferiores (valores de $p$ 0,01, 0,01, 0,003, 0,002 e 0,003, respectivamente). Nossos resultados sugerem que 0 grupo de países que aceitaram o OPCP está mais comprometido com as questões das causas de morte infantil estudadas. Em todos eles, os números anuais de mortalidade eram consideravelmente mais baixos nesse grupo.

\section{Palavras-chave}

Saúde da Criança. Cooperação Internacional. Direitos Humanos. Análise de Variância.

\section{Resumen}

La Convención sobre los Derechos del Niño y el Protocolo facultativo de la Convención sobre los Derechos del Niño Relativo a un Procedimiento de Comunicaciones (PFPC) establecen compromisos y garantías en relación con la salud infantil. El objetivo del estudio es verificar los efectos de estos compromisos sobre las causas de muerte infantil. Para analizar estos efectos, aplicamos el análisis de varianza unidireccional. Para cada grupo, calculamos los promedios de muertes infantiles en sus respectivos países para los años 2002, 2007, 2012 y 2017. El valor p resultante indicó si había una diferencia entre los promedios de muertes infantiles en los años comparados. También observamos la serie de tiempo para cada causa de muerte durante los años 2000 a 2017. El CRC tiene una adherencia significativa. OPCP tiene menos aceptadores en todas las regiones en comparación con CRC. La aceptación del OPCP no cambió significativamente los resultados del número de muertes en los países receptores en ninguna de las 13 causas observadas de muerte infantil. En el grupo de no aceptación, se encontraron diferencias significativas en relación con cinco causas de muerte infantil: VIH/SIDA, enfermedades diarreicas, sarampión, meningitis/encefalitis e infecciones respiratorias bajas agudas (valores de $p 0.01,0.01,0.003,0.002$ y 0,003 , respectivamente). Nuestros resultados sugieren que el grupo de países que ha aceptado el OPCP está más comprometido con los temas de causas de muerte infantil estudiados. En todos ellos, las cifras de mortalidad anual fueron considerablemente menores en este grupo.

\section{Palavras clave}

Salud del Niño. Cooperación Internacional. Derechos Humanos. Análisis de Varianza.

\section{Introduction}

The United Nations Convention on the Rights of the Child (CRC) entered into force in the international order in September 1990. It is a remarkable legal instrument and has influenced constitutions, legislation in general, court decisions, public policy and the work of international organizations (1). 
Countries that adhere to the CRC are committed to the protection of children and the care necessary for their well-being and must take legislative and administrative measures to ensure this (2).

Specifically in relation to health, article 24 of the CRC establishes that States Parties recognize the child's right to the enjoyment of the best possible standard of health and services aimed at the recovery and treatment of illnesses. It also mentions the efforts that must be made to fight malnutrition and diseases related to basic health care. Another 10 articles in the CRC mention the child's health as an important factor for the adoption of measures (3).

This demonstrates that the health issue is widely addressed at the CRC. States Parties undertake not only to protect against deprivation of access to health services, but also to promote access, that is, by identifying and eliminating financial, institutional and cultural barriers (1).

$\mathrm{CRC}$ has three optional protocols as well as other international human rights treaties. One related to the involvement of children in armed conflicts, another to sale, pornography and child prostitution, and a third related to communication procedures. The protocols act as additional articles and are valid only for the parties that accept them (4). Only countries that adhere to the CRC can commit to its optional protocols. But these have a certain autonomy, because a country can join the CRC but not ratify the protocols, or ratify just one of them.

The Optional Protocol to the Convention on the Rights of the Child on a Communications Procedure (OPCP) deals with a committee that will exercise jurisdiction in relation to violations of the rights of the $\mathrm{CRC}$ and the other two protocols. It is an instrument, therefore, not for the creation of rights, but for guarantees. The OPCP provides for mechanisms capable of resolving conflicts and violations that may eventually be communicated to the committee (5).

The existence of legal instruments in the international order that protect children's health is undoubtedly a remarkable advance. However, it is necessary to know whether these commitments have any effect in terms of realizing legal protection. Does the fact that countries become part of an international agreement, accepting international child health standards, motivate them to implement efforts to fulfill the obligations that flow from those standards?

To answer this question, there are several possible paths. There is a study (6) that observed the evolution of the low weight of children younger than five years of age and the 
child mortality rate in the period from 1990 to 2009. Study conducted in 2009 (7) worked with indicators of mortality rate for children younger than five years and maternal mortality rate to test the association between ratification of the CRC and improvement in those indicators. No statistically significant differences were found in the indicators between countries that ratified the treaty and those that did not.

The literature lacks further studies on the effects of international commitments on child health and this work intends to contribute to this question. Thus, the aim of this study is to verify the effects of the OPCP on the causes of child death.

\section{Methods}

This study used statistical methods to verify the effects of the OPCP on the causes of child death.

First, it was calculated the percentage of countries that ratified the $\mathrm{CRC}$ and the percentage of those that accepted OPCP from Office of the United Nations High Commissioner for Human Rights (OHCHR) databases (8). The bank covers all 198 countries. Of these 198, we used the 194 countries recognized by WHO, because we organized the results by WHO regions to see the percentage of ratification and adherence in each area. There are six WHO regions: Africa (47 countries), Americas (35 countries), Eastern Mediterranean (21 countries), Europe (53 countries), South-East Asia (11 countries), and Western Pacific (27 countries) (9).

Regarding the causes of child deaths, we worked with the indicator number of deaths due to a specific cause, among five-year-old children, from the WHO Global Health Observatory data repository, which contains 13 items: i) HIVIAIDS, ii) diarrhoeal diseases, iii) measles, iv) meningitis/encephalitis, v) malaria, vi) acute lower respiratory infections, vii) prematurity, viii) birth asphyxia and birth trauma, ix) sepsis and other infectious conditions of the newborn, $x$ ) other communicable, perinatal, and nutritional conditions, $x i)$ congenital anomalies, xii) other noncommunicable diseases, and xiii) injures.

Each item has annual data on the number of child deaths from all 194 countries over the period of 2000 to 2017 (10).

To analyze the effects of OPCP we applied the one-way analysis of variance (11). For this analysis, we divided the 194 countries into two groups: OPCP accepting and nonaccepting countries. For each group, we calculated the averages of child deaths in their respective countries for the years $2002,2007,2012$, and 2017 , which gave rise to six possible 
comparisons (two-by-two comparisons regardless of order). The $p$-value resulting from the one-way variance analysis indicated whether there was a difference between the means of child deaths in those years that were compared. We considered $p$-values less than 0.05 to be a significant difference. These results were presented on the logarithmic scale.

We also observed the time series for each cause of death over the years 2000 to 2017. The countries were divided into the same two groups of OPCP accepting and non-accepting countries. We built scatter plots with absolute values and with relative values for each cause of infant death to infer the trend in the evolution of the number of deaths. The analysis carried out between the years of 2000 to 2017 covered the longest period possible, as the WHO database of causes of child death starts with data from the 2000 and ends with data from 2017.

The one-way variance analysis assumes that the observations are independent and were randomly selected from an average population with equal variances (11). The limit of this research is that these assumptions are not met. All data used in this work are secondary and public.

\section{Results}

The CRC has an expressive adhesion, as shown in Figure 1 (a). The only country in the world that has not ratified it was the United States (US) and for this reason, the region of the Americas accounts for $97 \%$ of adhesion, while all the others accounted for $100 \%$.

Figure 1. Distribution of ratification by countries to the Convention on the Rights of the Child (a) and acceptance of individual communications and inquiry procedure (b), by regions, $N=$ 194,2020

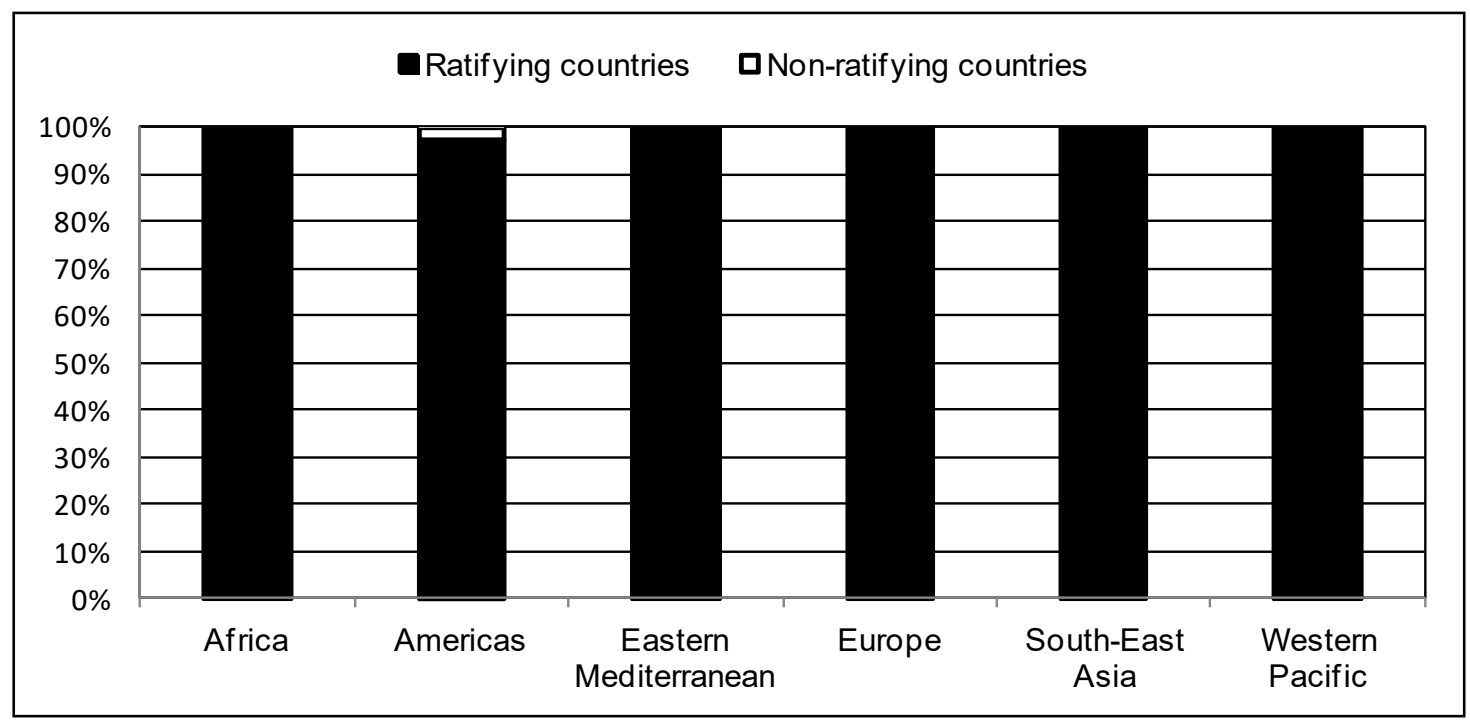

(a) 


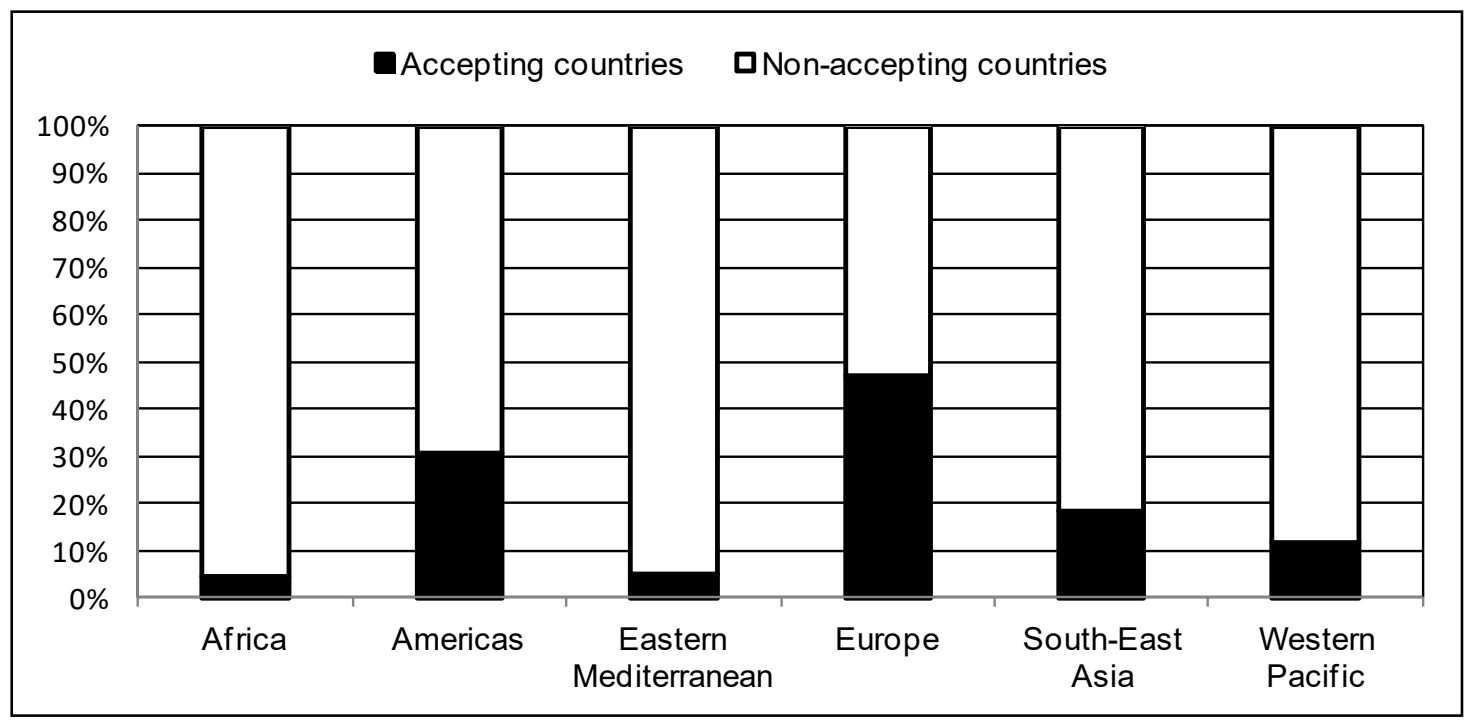

(b)

Source: Office of the United Nations Commissioner for Human Rights

OPCP has a smaller number of acceptors in all regions compared to CRC. Figure 2 (b) indicates that Africa and Western Pacific are the regions with the lowest levels of commitment, respectively $4 \%$ and $11 \%$. Europe is the region with the most substantial number of countries accepting OPCP, with $47 \%$ acceptance. Table 1 presents the results of the one-way variance.

Table 1. One-way variance of the decimal logarithm regarding the number of child deaths in the accepting countries $(N=44)$ and in the non-accepting countries $(N=150), 2002-2017$

\begin{tabular}{lcc}
\hline \multicolumn{1}{c}{ Causes of child death } & \multicolumn{2}{c}{$p$-value } \\
\cline { 2 - 3 } & $\begin{array}{c}\text { Signatory } \\
\text { countries }\end{array}$ & $\begin{array}{c}\text { Non-signatory } \\
\text { countries }\end{array}$ \\
\hline HIVIAIDS & 0.29 & 0.01 \\
Diarrhoeal diseases & 0.68 & 0.01 \\
Measles & 0.92 & 0.003 \\
Meningitis/encephalitis & 0.07 & 0.002 \\
Malaria & 0.58 & 0.72 \\
Acute lower respiratory infections & 0.53 & 0.003 \\
Prematurity & 0.86 & 0.27 \\
Birth asphyxia and birth trauma & 0.9 & 0.093 \\
Sepsis and other infectious conditions of the newborn & 0.9 & 0.37 \\
Other communicable, perinatal and nutritional conditions & 0.99 & 0.61 \\
Congenital anomalies & 0.54 & 0.48 \\
Other noncommunicable diseases & 0.59 & 0.39 \\
Injuries & 0.45 & 0.14 \\
\hline
\end{tabular}

Source: WHO - Global Health Observatory data repository 
The acceptance of OPCP did not significantly alter the results of the number of deaths in the accepting countries in any of the 13 causes of child death observed. In the nonaccepting group, significant differences were found concerning five causes of child death: HIVIAIDS, diarrhoeal diseases, measles, meningitis/encephalitis, and acute lower respiratory infections ( $p$-values $0.01,0.01,0.003,0.002$, and 0.003 , respectively).

Although the variations registered in the accepting countries were not significant, when verifying the averages of these countries it is possible to notice that they were smaller than the averages of the non-accepting countries (in all causes of death and all the years studied). Figure 2 shows this.

Figure 2. Time series regarding the number of child deaths in the accepting countries $(\mathrm{N}=$ $44)$ and in the non-accepting countries ( $N=150), 2000-2017$

HIVIAIDS

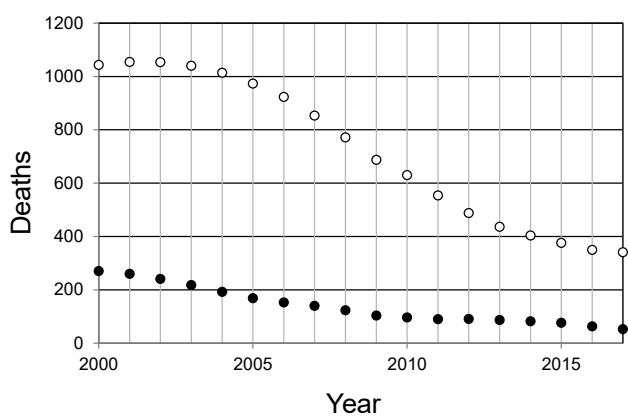

Measles

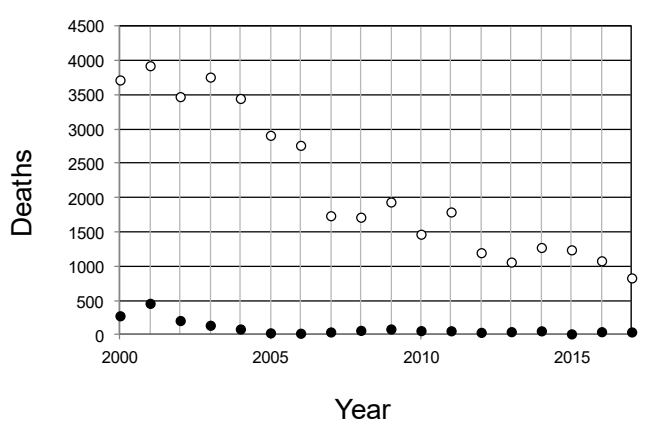

Malaria

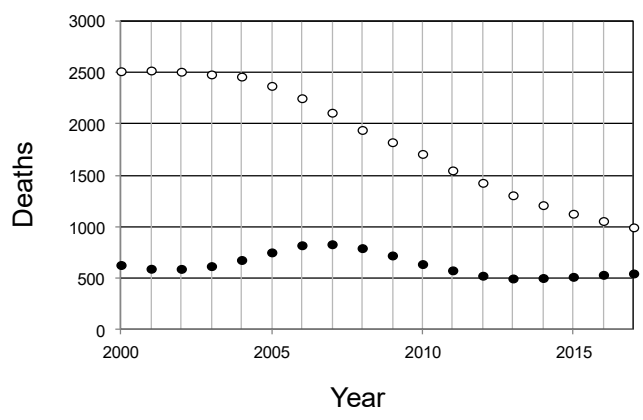

Prematurity
Diarrhoeal diseases

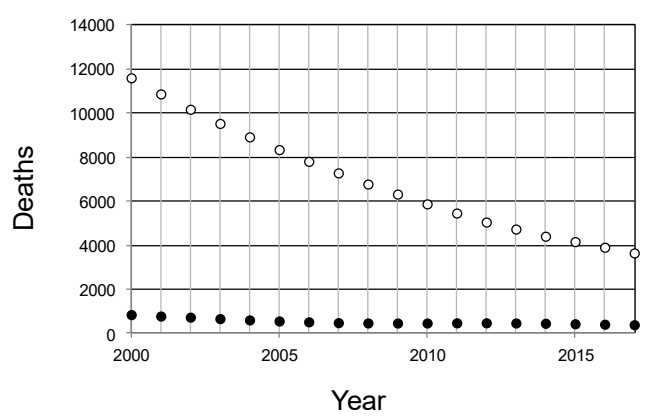

Meningitis/encephalitis

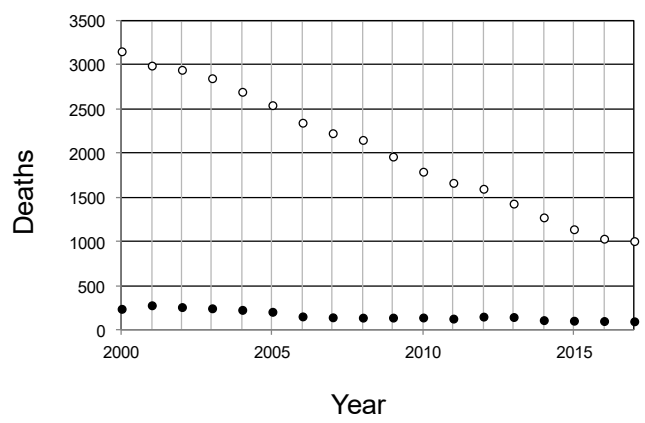

Acute lower respiratory infections

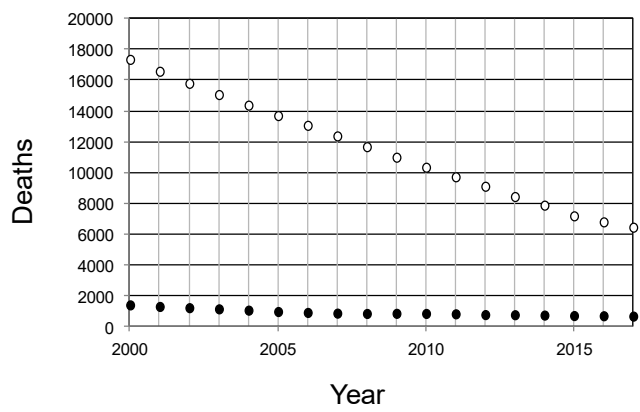

Birth asphyxia and birth trauma 


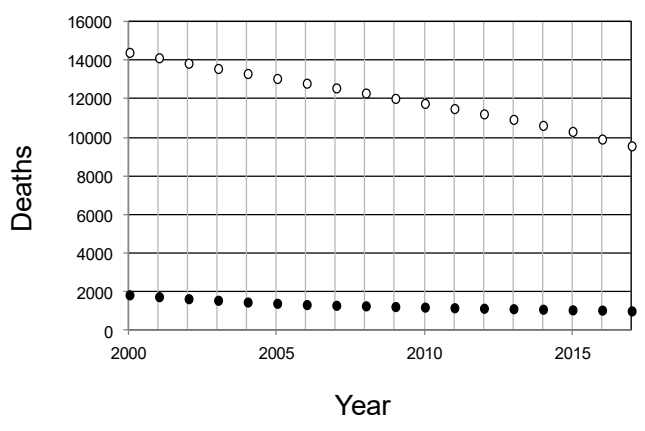

Sepsis and other infectious conditions of the newborn

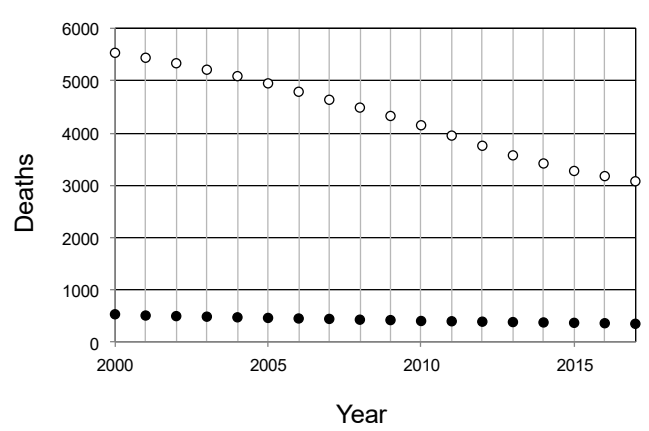

Congenital anomalies

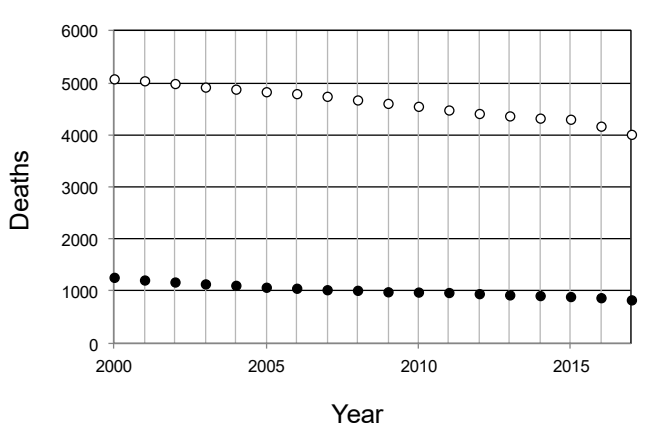

Injuries

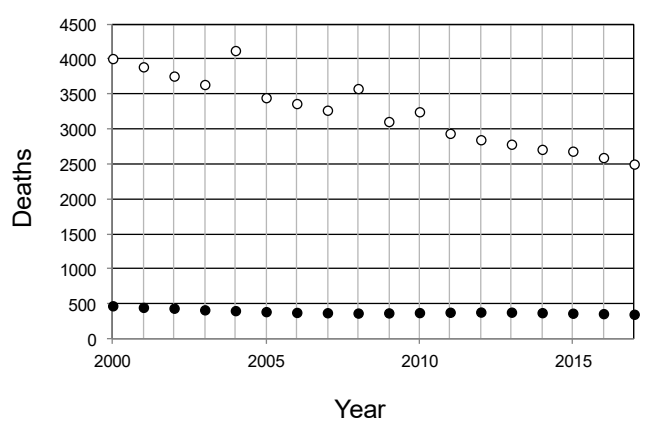

○ Non-accepting countries

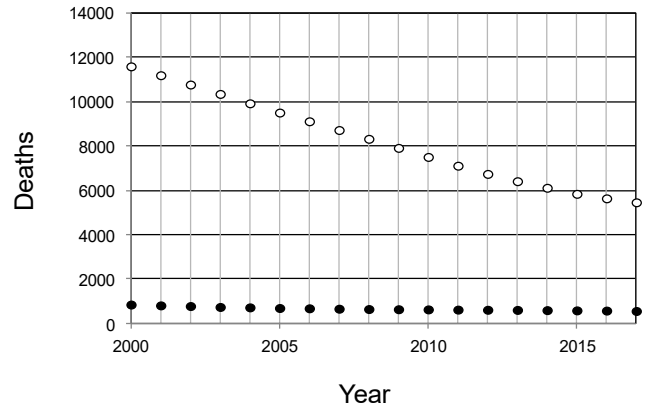

Other communicable, perinatal and nutritional conditions

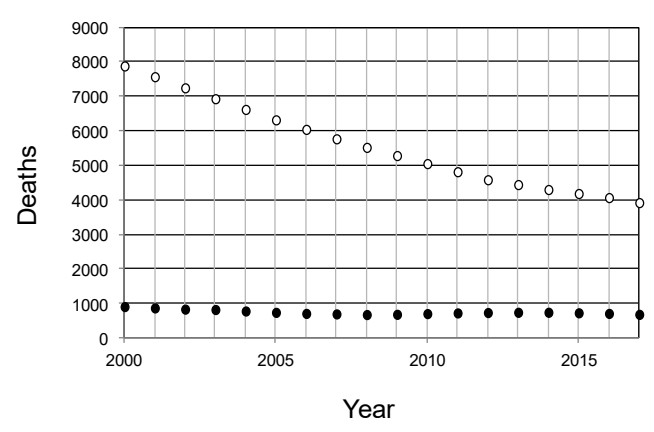

Other noncommunicable diseases

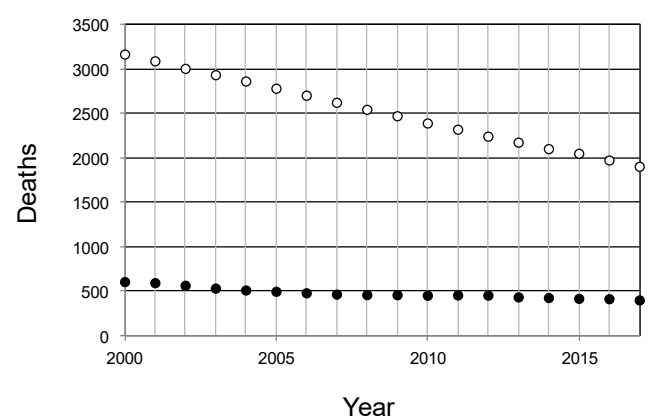

Source: WHO - Global Health Observatory data repository 
Figure 2 also shows that all-cause of child death curves for non-accepting countries have a downward trend. Acute lower respiratory infections and diarrhoeal diseases showed the most considerable decrease in absolute numbers of deaths. They computed, respectively, a difference of 10,879 and 7,847 between the years 2000 and 2017. In relative terms, measles recorded the most substantial decrease in the period, $78 \%$, with diarrhoeal diseases coming soon after, with a reduction of $68 \%$.

Still, in non-accepting countries, the worst results in absolute numbers were in HIVIAIDS, with a reduction of 702 deaths, and in congenital anomalies, with a reduction of 1,066 deaths in this period. Congenital anomalies also registered the lowest percentage of reduction, $21 \%$, and as the second-worst percentage, acute lower respiratory infections, with a reduction of $34 \%$.

Considering accepting countries, in absolute terms, the decline in curves, in general, was less than that of non-accepting countries. Acute lower respiratory infections and prematurity were the most substantial decreases in absolute numbers of deaths, with respective differences of 834 and 727 between the years 2000 and 2017 . When comparing in percentage terms, the most considerable decrease was in HIVIAIDS, with a reduction of $80 \%$, and the second-best result was meningitis/encephalitis with $58 \%$.

The worst results in the accepting countries, both in absolute terms and in percentage terms, were in measles and malaria. Measles had a reduction of 20 deaths $(7 \%)$, while malaria had a reduction of 82 deaths $(13 \%)$, during this period.

Figure 3 compares the performance of child deaths concerning the initial value from accepting and non-accepting countries in percentage terms.

Figure 3. Time series regarding the percentage of child deaths concerning the initial value in the accepting countries $(N=44)$ and in the non-accepting countries $(N=150), 2000-2017$

HIVIAIDS

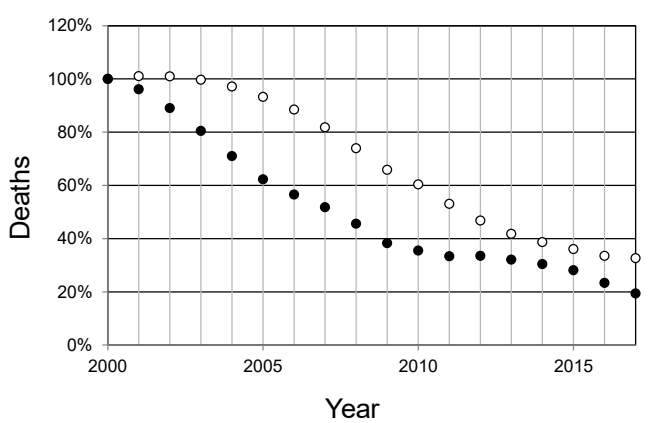

Diarrhoeal diseases

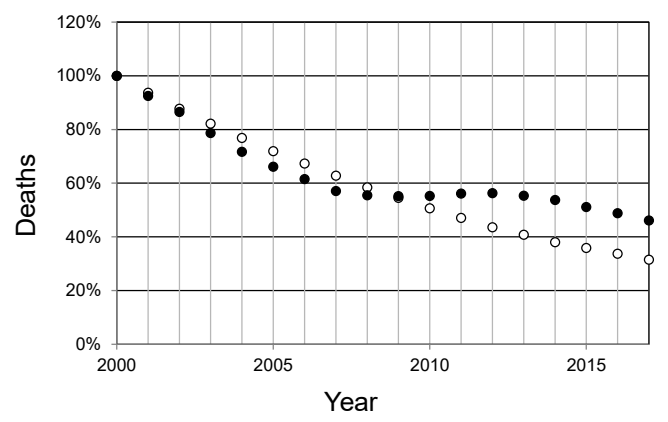




\section{Measles}

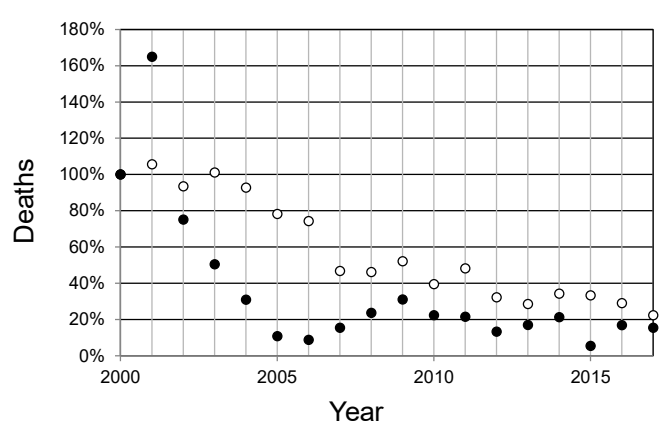

Malaria

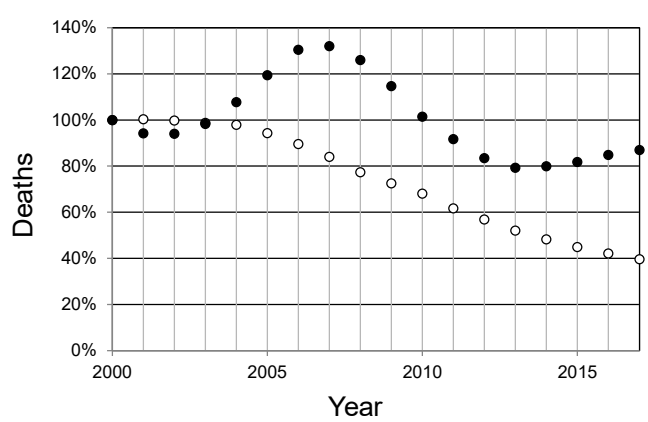

Prematurity

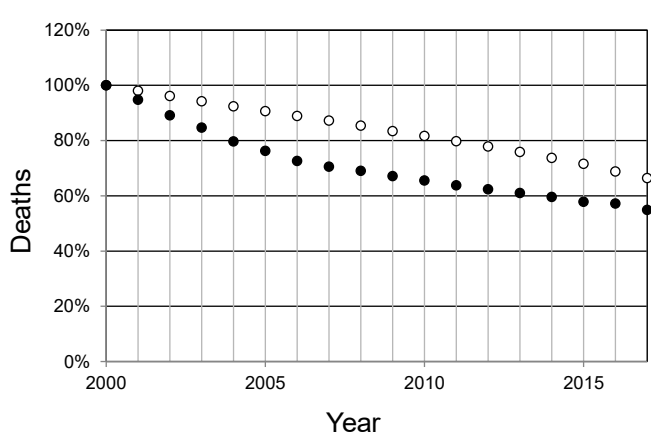

Sepsis and other infectious conditions of the newborn

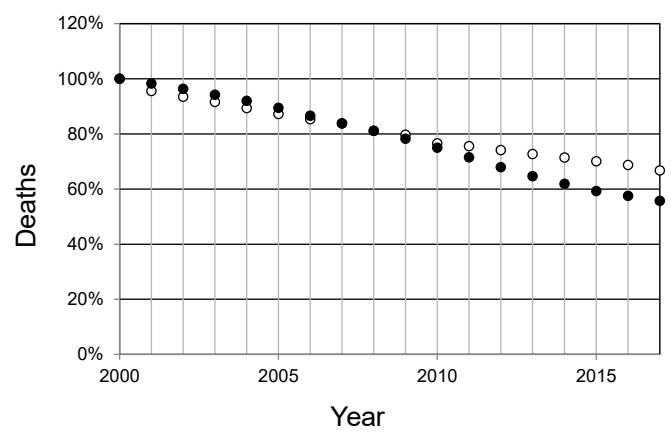

Meningitis/encephalitis

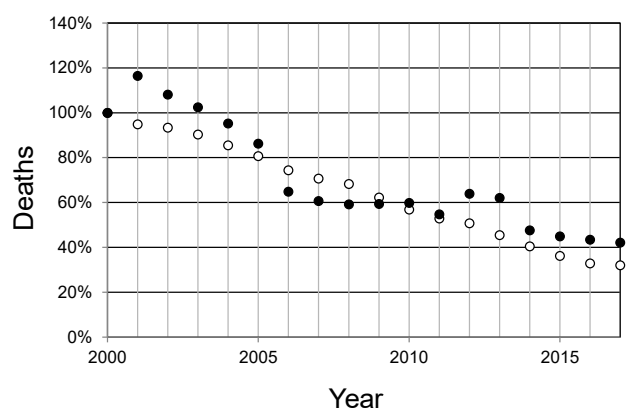

Acute lower respiratory infections

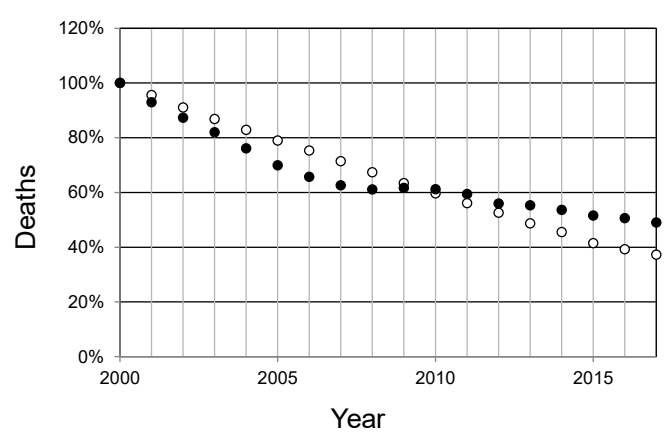

Birth asphyxia and birth trauma

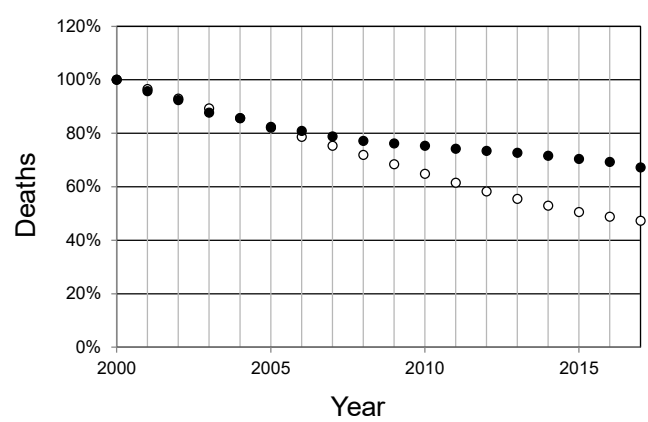

Other communicable, perinatal and nutritional conditions

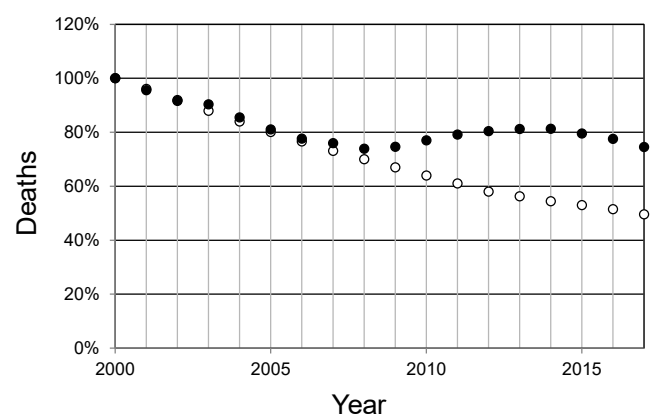


Congenital anomalies

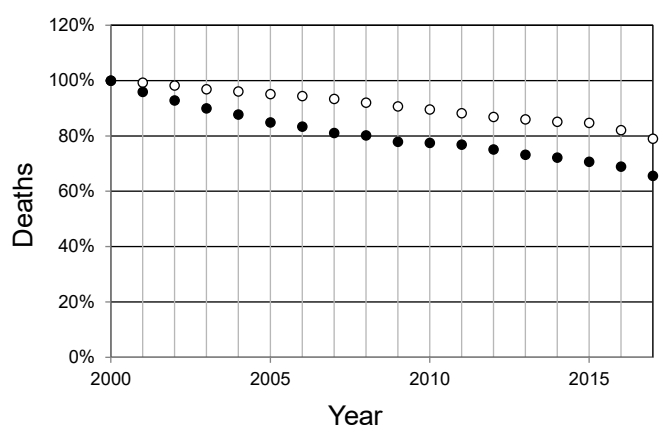

Injuries

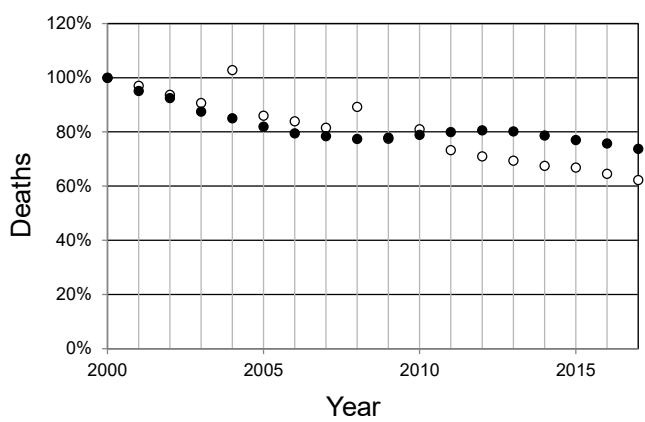

Other noncommunicable diseases

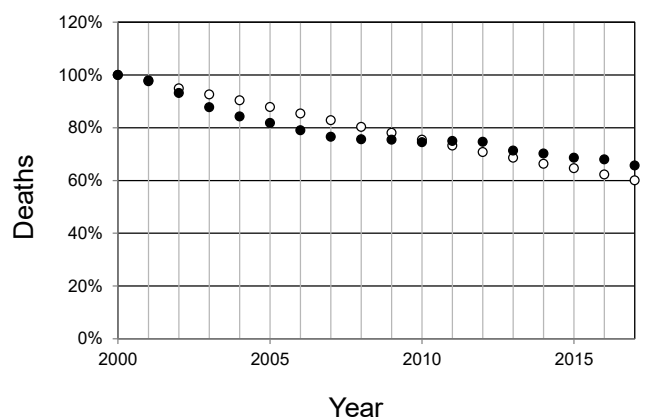

○ Non-accepting countries

- Accepting countries

Source: WHO - Global Health Observatory data repository

In both groups of countries, the trend of the time series trend decreased for most causes of child death. However, the difference in the rate of decline was not as marked as seen in Figure 2.

The most similar curves, that is, with minor variations between groups of countries, were other non-communicable diseases and acute lower respiratory infections. Diarrhoeal diseases, birth asphyxia and birth trauma, sepsis and other infectious conditions of the newborn, and other communicable, perinatal, and nutritional conditions were similar until approximately 2008 to 2010 . After that, the accepting countries showed a smaller percentage reduction, except for sepsis.

The case of malaria drew attention. The percentage of deaths in accepting countries higher than those of non-accepting countries was also an upward trend from early 2002 to 2007. As of 2014, the percentage of deaths rose again in accepting countries and seems to follow a new downward trend, albeit at a lower rate than that observed from 2002 to 2007. 
The most considerable distance between the curves for these groups of countries occurred in 2005 in the percentage of deaths from measles, with a difference of 68 percentage points. In the following years, there was an increase in the accepting countries, which made the difference between the two smaller.

\section{Discussion}

The results showed that the $\mathrm{CRC}$ is a worldwide consensus. It is among the conventions with the highest number of ratifications in the world. This high level of adherence already has a significant meaning, because countries recognized that children live under challenging conditions and that something needed to be done (2).

Only the US has not ratified the CRC. However, they are signatories, which shows that they have started the process, but have not finished it. The reasons for non-ratification are related to the Convention's clash with US domestic laws. Article 3/1 of the Convention, for example, establishes the best interests of the child as a principle to be considered in all actions concerning the child. Although it was not a new principle, for the first time, the law emphasizes it universally (2). US parent law organizations opposed ratification of the CRC because they feared empowering children, which could affect a family relationship. However, this is not a real problem. While American states are free to adopt the best interest standard, today they all have laws that adhere to that standard. Thus, the implementation of the CRC would require little or no legislative adjustment. The truth is that in recent decades, the US has not ratified other international human rights treaties for internal reasons linked to sovereignty, such as the preservation of the rights of States, constitutional issues, and fear of foreign interference in its legal system (12).

Another factor that drew attention to the survey results was the difference between the degree of adherence to the CRC and the OPCP. While the CRC is practically unanimous, the OPCP has been ratified by the fewest countries in all regions. The Protocols oblige countries to take a more active role in child protection. The CRC does not provide an effective mechanism for the concrete application of its provisions, as occurs in other international human rights documents (13). It created the Committee on the Rights of the Child to monitor its implementation (2), but in practice, it is a body that interprets the Convention and issues recommendations (13). The Protocol, on the other hand, creates mechanisms for filing complaints in case of violations of children's rights, which can be presented by children 
individually or in groups of children. The Protocol also allows the Committee to take provisional measures to prevent irreparable harm (13).

Considering the results consolidated in Figure 1, we can conclude that countries are committed mainly to the complete system of child rights. Still, the low rate of adherence to the OPCP shows that, in general, countries are not open to an international forum that can examine possible violations of children's rights in their territories.

The results of the one-way variance analysis were surprising because they were contrary to the initial research hypothesis. Only countries not committed to the OPCP showed significant reductions in child deaths for 5 of the 13 causes of death studied. In the group of countries committed to the OPCP, there was no significant change in this regard. However, when analyzing the time series of the number of each cause of death, we observed that there was a difference in the order of magnitude of the number of deaths between the groups of countries committed to and those not committed to the OPCP, as shown in Figure 2. Countries not committed to the OPCP counted deaths in the thousands for most of the causes of infant death, while those committed estimated deaths in the order of hundreds. Thus, although the countries committed to the OPCP did not show statistically significant reductions in the number of deaths, it did not mean that these issues were more serious problems than in the group of non-committed countries.

When exploring the time series presented in relative ways, as in Figure 3, what can be seen is that there is no order of magnitude difference in the reductions in general, as observed in the curves of the absolute numbers. This demonstrates that committed countries, even with a lower number of deaths, managed to maintain a pattern of percentage reduction close to that of non-committed countries.

These analyzes lead us to develop new hypotheses. Thinking that the countries that commit to the OPCP are those that already direct public policies to improve the living conditions of children. As if the commitment to international legal instruments that have tools to guarantee their implementation, as in the case of the OPCP, were not the cause, but the consequence, a kind of confirmation of rights and mechanisms that domestic legislation already guarantees.

Another study analyzed the effectiveness of CRC on aspects of children's lives and one of the factors observed was the mortality rate (14). The evidence from this work showed that the CRC was successful, as this rate dropped from 99 to 66 per 1000 live births between 
1990 and 2009 and this drop was attributed to the incorporation of the CRC into the countries' national legislation.

Our results do not conflict with those of this research. If we consider that practically all the countries in the group not committed to the OPCP ratify the CRC (the only exception being the USA), we would also conclude that after the internalization of the CRC, the numbers of child deaths suffered essential reductions. However, the objective of our research was to analyze from another aspect, trying to form a kind of control group to observe the results in countries not committed to the treaty.

This type of study with the CRC would not be possible, because since the late 1990s the rate of commitment of countries to this convention was already above $96 \%$ (8). The indices of commitment to the OPCP were lower and allowed this type of comparison. Added to this, the OPCP is more forceful in establishing mechanisms for reporting and decisionmaking in the face of violations of children's rights. The country that commits to the OPCP seems to be more willing to implement targeted health policies for children than those that just ratified the CRC. Our results showed that countries committed to the OPCP had lower levels of child deaths from the observed causes.

Almost all cases studied, except malaria, reduced the number of child deaths over the past few years. Five of these causes had a satisfactorily significant reduction, as seen in Table 1, namely: HIVIAIDS, diarrhoeal diseases, measles, meningitis/encephalitis, and acute lower respiratory infections.

The literature also points to a substantial decrease in deaths from HIVIAIDS in children and links it to the expansion of prevention of mother-to-child transmission (15). Our results showed that countries not committed to the OPCP, despite a small increase between the years 2000 and 2001, the subsequent years were in decline. Countries committed to the OPCP also registered a decline, which was not statistically significant (Figure 2). However, when comparing the evolutions in relative terms, as in Figure 3, we observe that the committed countries registered higher reduction percentages than the countries in the other group.

A study that analyzed the evolution of diarrheal diseases in the world showed a decrease of about $20.8 \%$ in the number of deaths in all age groups from 2005 to 2015, and a reduction in the mortality rate among children under 5 years of age of $39.2 \%$ in the same period (16). This reduction also appeared in our results and was statistically significant for countries not committed to the OPCP. In percentage terms, as shown in Figure 3, the two 
groups of countries maintained a similar reduction until the years 2010. In later years, countries committed to the OPCP continued to show a decrease in deaths, but in smaller percentages than the other countries.

In the case of measles, this reduction is related to the increase in vaccination coverage. It is estimated that immunization programs reduced $87 \%$ in incidence, with an $84 \%$ reduction in measles mortality between 2000 and 2016 (17). Comparing our results with this study, both demonstrate an important reduction in the number of deaths from measles in the last two decades. However, our results show that the group of countries committed to the OPCP had a lower number of measles deaths (average of approximately 100 deaths between 2000 and 2017 against the average of approximately 2184 of non-committed countries). In addition, countries committed to the OPCP maintained a lower percentage of measles deaths than non-committed countries throughout practically the entire period, as shown in Figure 3.

The WHO has developed a goal to eradicate meningitis/encephalitis by 2030 (6). Our findings show that there was an overall reduction, which may already be the effects of these international efforts to reach the goal. The statistically significant reduction occurred only in the group of countries not committed to the OPCP. However, as in the case of diarrheal diseases, the percentage reductions in the number of deaths were similar in the two groups in the period observed.

About child deaths from acute lower respiratory infections, the results of this survey showed a reduction in the two groups of the countries studied. This is in line with recent research, which also pointed to substantial progress in reducing the burden of this disease (18). Once again, although statistical significance was only found in the group of countries not committed to the OPCP when analyzing the percentage reduction in the number of deaths, it is possible to notice that the pattern of decrease was similar in the period between the two groups.

Malaria was the only cause of death that showed an increasing trend at any given time in the time series and this occurred in the group of countries committed to the OPCP. The growth was registered in the years 2002 to 2007, with a subsequent drop in subsequent years, but it starts to grow again from 2014 onwards. This curve is more evident in Figure 3.

\section{Conclusions}

The CRC has practically unanimous worldwide membership, which was not observed in the OPCP membership. Countries are broadly committed to the children's rights enshrined 
in the CRC, but the percentage of countries that accept the handling of international instruments in the event of violations of these rights, as provided for in the OPCP, is substantially lower.

Ratifying a treaty like the CRC is an important political act, which can motivate many countries to adhere to it with the aim of protocol, that is, to demonstrate that those rights and principles are formally respected in their respective territories. It is true that the high level of membership of the CRC is something successful in itself, because the recognition of the existence of the right is already an advance. However, it represents the first step towards effective protection of rights. Other steps need to be taken.

Adhering to a protocol that exposes the country to complaint mechanisms regarding respect for these rights, as is the case with the OPCP, requires a greater and true commitment to the rights enshrined in the main convention.

Our results suggest that the group of countries that have accepted the OPCP are more committed to issues of child deaths causes studied. In all of them the annual death numbers were considerably lower in this group. This fact makes us think that adherence to the OPCP does not produce practical effects in terms of improving the number of child deaths, but it can be an indicator of the level of effort to do so. Because it is the countries that have the best results in these data that have committed to the OPCP.

\section{References}

1. Tobin J. The UN Convention on the Rights of the Child: a commentary. $1^{\circ}$ edition. Oxford: Oxford University Press; 2019. 1823 p.

2. Jancic OC. The Rights of the Child in a Changing World: 25 years after the UN Convention on the Rights of the Child. Switzerland: Springer International Publishing; 2016. $410 \mathrm{p}$.

3. UN. Resolution 44, on September 25, 1990. Establishes the Convention on the Rights of the Child. United Nations General Assembly, September 25, 1990 [cited on August 12, 2021]. Available in: https://www.ohchr.org/Documents/Professionallnterest/crc.pdf

4. Crivelli DE. The Italian debate about the ratification of Protocol. Riv Eurojus. 2020;11(4):1-11.

5. UN. Resolution 66/138, January 27, 2012. Establishes the Optional Protocol to the Convention on the Rights of the Child on a communications procedure. United Nations General Assembly, January 27, 2012 [cited on August 12, 2021]. Available in: https://resourcecentre.savethechildren.net/node/15175/pdf/n1146710.pdf 
6. Wright C, Blake N, Glennie L, Smith V, Bender R, Kyu H, et al. The Global Burden of Meningitis in Children: Challenges with Interpreting Global Health Estimates.

Microorganisms. 2021; 377(9):1-16.

7. Palmer A, Tomkinson J, Phung C, Ford N, Joffres M, Fernandes KA, et al. Does ratification of human-rights treaties have effects on population health? The Lancet. 2009; 373(9679):1987-92.

8. OHCHR: Convention on the Rights of the Child [Internet]. Status of Ratification. 2021 [cited on June 15, 2021]. Available in: https://indicators.ohchr.org/

9. WHO: World Health Organization Countries Classification. [Internet]. Countries. 2021 [cited on June 15, 2021]. Available in: https://www.who.int/countries

10. WHO: The Global Health Observatory data repository: deaths in children aged <5years, by cause. [Internet]. Number of deaths by country. 2021 [cited on June 15, 2021]. Available in: https://apps.who.int/gho/data/node. main.ChildMortCTRY1002015?lang=en

11. Bewick V, Cheek L, Ball J. Statistics review: One-way analysis of variance. Crit Care. 2004; 8(2):130-136.

12. Demleitner NV. The State, Parents, Schools, "Culture Wars," and Modern Technologies: Challenges under the U.N. Convention on the Rights of the Child. Am J Comp LAW. 2014; 62:24.

13. Hrabar D. Bridging the non-protection of children's rights through the Optional Protocol to the CRC on communications procedure and a future european court. Godisnjak Akademije pravnih znanosti Hrvatske. 2017; 22(3):13-33.

14. Wilson A, Daar AS. A Survey of International Legal Instruments to Examine Their Effectiveness in Improving Global Health and in Realizing Health Rights. J Law Med Ethics. 2013;41(1):89-102.

15. Frank TD, Carter A, Jahagirdar D, Biehl MH, Douwes-Schultz D, Larson SL, et al. Global, regional, and national incidence, prevalence, and mortality of HIV, 1980-2017, and forecasts to 2030, for 195 countries and territories: a systematic analysis for the Global Burden of Diseases, Injuries, and Risk Factors Study 2017. Lancet HIV. 2019;6(12):e83159.

16. Troeger C, Forouzanfar M, Rao PC, Khalil I, Brown A, Reiner RC, et al. Estimates of global, regional, and national morbidity, mortality, and aetiologies of diarrhoeal diseases: a systematic analysis for the Global Burden of Disease Study 2015. Lancet Infect Dis. 2017;17(9):909-48.

17. Griffin DE. Measles virus and the nervous system. In: Tselis AC, Booss J, editors. Handbook of Clinical Neurology. $3^{\text {rd }}$ series. Elsevier; 2014. p. 577-590.

18. Troeger C, Blacker B, Khalil IA, Rao PC, Cao J, Zimsen SRM, et al. Estimates of the global, regional, and national morbidity, mortality, and aetiologies of lower respiratory 
infections in 195 countries, 1990-2016: a systematic analysis for the Global Burden of Disease Study 2016. Lancet Infect Dis. 2018;18(11):1191-210.

\section{Colaboradores}

Nichele CST contributed to the conceptualization of the article, data collection and analysis, article writing, and final approval of the version to be published. Pereira Horta MA contributed to the conceptualization of the article, data collection and analysis, and final approval of the version to be published. Ferreira AP contributed to the conceptualization of the article, data collection and analysis, critical review of the article, and final approval of the version to be published.

\section{Como citar este artigo}

Nichele CST, Pereira Horta MA, Ferreira AP. Effects of the Optional Protocols to the Convention on the Rights of the Child on the causes of child death: a statistical study on a global scale. Cadernos Ibero-Americanos de Direito Sanitário. 2021 out./dez.;10(4):48-65.

https://doi.org/10.17566/ciads.v10i4.819 